\title{
A reduction in the sea surface warming rate in the South China Sea during 1999-2010
}

\author{
Guo-Qing Jiang ${ }^{1,2} \cdot$ Qinjian Jin $^{3} \cdot$ Jun Wei ${ }^{4,5} \cdot$ Paola Malanotte-Rizzoli $^{2} \cdot$ Arnold L. Gordon $^{6} \cdot$ Mingting Li $^{4,5}$
}

Received: 2 July 2020 / Accepted: 30 April 2021 / Published online: 21 May 2021

(c) The Author(s) 2021

\begin{abstract}
The South China Sea (SCS) experienced a significant reduction in warming rate $\left(-0.01{ }^{\circ} \mathrm{C}\right.$ decade $\left.^{-1}, p>0.10\right)$ during 1999-2010 following an accelerated and unprecedented warming $\left(+0.15^{\circ} \mathrm{C}\right.$ decade $\left.^{-1}, p<0.01\right)$ in the last three decades (1970-1998). However, most global climate models of the CMIP5 RCP4.5 scenario failed to capture this SCS warming slowdown. In this study, we identify two drivers through numerical simulations by using a regional high-resolution, oceanatmosphere coupled climate model: the major variance (75\%) in the sea surface warming slowdown could be explained by the strengthened winter monsoon over the SCS, and the minor variance (12\%) could be explained by the changes in the upper ocean circulations. The winter monsoon over the SCS is likely linked to the La Niña-like SST pattern in the eastern tropical Pacific, which strengthens the Walker circulation and results in anticyclonic circulation over the northwestern Pacific. This enhanced winter monsoon is the atmospheric driver that slows down the SCS basin-scale warming, while the largest reduction of the warming rate occurs in the northern SCS that can be attributed to the oceanic throughflow via the Luzon Strait. These findings could have important implications for future climate projections over the SCS and adjacent oceans.
\end{abstract}

\section{Introduction}

The South China Sea (SCS), surrounded by 13 Southeast Asian countries that are home to over 600 million people, is strategically crucial in shipping goods, lucrative fisheriesbased food security, and large oil-gas reserves. Hence, the spatiotemporal variability in the SCS ocean-climate system has immeasurable impacts on human economic activities (He et al. 2014; Tong et al. 2017), ecosystem stability,

Jun Wei

weijun5@mail.sysu.edu.cn

$1 \quad$ BaiDu Inc., Beijing 100080, China

2 Department of Earth, Atmosphere and Planetary Sciences, Massachusetts Institute of Technology, Boston 02139, USA

3 Department of Geography and Atmospheric Science, University of Kansas, Lawrence, KS, USA

4 Key Laboratory of Tropical Atmosphere-Ocean System, Ministry of Education, School of Atmospheric Sciences, Sun Yat-Sen University, Guangzhou 510275, China

5 Southern Marine Science and Engineering Guangdong Laboratory (Zhuhai), Guangdong, China

6 Lamont-Doherty Earth Observatory, Columbia University, Palisades, NY 10027, USA natural disasters, such as typhoon intensity (Guo and Tan 2018), and SCS summer monsoon onset (Wu 2010).

Embedded between the tropical Indian and Pacific Oceans, the complex climate variability in the SCS is driven by both local air-sea interactions and large-scale remote forcing through oceanic and atmospheric bridges (Gordon 1986; Klein et al. 1999; Wei et al. 2016a). The SCS is injected with western tropical Pacific water by the Luzon Strait and exports water through the Karimata Strait into the Java Sea (Du and Qu 2010; Qu 2000) and the Mindoro-Sibutu pathway into the Sulu Sea (Gordon et al. 2012; Jiang et al. 2019; Li et al. 2018, 2019, 2020; Metzger and Hurlburt 1996). The SCS experiences strong seasonality due to variability in solar radiation and monsoonal forcing (Chen et al. 2003b; He and Wu 2013; Liu et al. 2001; Qu 2001); in addition, there is interannual variability induced by remote forcing from tropical oceans, such as the El Niño-Southern Oscillation (ENSO) (Liu and Xie 1999; Wei et al. 2016a). On a longer timescale, the SCS has experienced accelerated and unprecedented warming since the 1970s. However, the SCS warming was believed to continue until recently according to many previous studies (Lin et al. 2011a, b; Thompson et al. 2017; Xiao et al. 2019; Yang and Wu 2012; Wei et al. 2013), as few of them focused on the SCS warming 
slowdown during 1999-2010, and the mechanisms have not been well addressed.

In the two decades following 1999, a so-called "hiatus" or slowdown of global surface warming was found (Abraham et al. 2013; Balmaseda et al. 2013; Levitus et al. 2009; Meehl et al. 2011). One explanation relates the "hiatus" to the Pacific Decadal Oscillation (PDO) and decadal ENSO signal (Lin et al. 2011a, b; Trenberth and Fasullo 2013). These studies found that the PDO shifted from a positive phase during 1976-1998 (warmer Indo-Pacific pool and cooler Western North Pacific) to a negative phase after 1999 (cooler Indo-Pacific pool and warmer Western North Pacific). During the PDO negative phase, the decadal Niña 3.4 index shows a predominant La Niña-like phase, which enhances trade winds and cools the eastern tropical Pacific. Given that the tropical Pacific largely accounts for the global surface temperature variation, the La Niña-like phase could make a significant contribution to the "hiatus" (Kosaka and Xie 2013). Other explanations, such as heat sinking into the deeper ocean (Chen and Tung 2014), natural variability and radiative forcing of the climate system (Dai et al. 2015; Huber and Knutti 2014; Watanabe et al. 2014), volcanic eruption (Santer et al. 2014), and increased Indonesian throughflow (ITF), which transfers Pacific heat into the Indian Ocean (Lee et al. 2015), were also found, arguing that global warming forced by a long-lasting surging trend of anthropogenic aerosol emissions will persist. Some climate model projections suggest that the "hiatus" may continue to the end of the 2020s (England et al. 2014; Medhaug et al. 2017).

The "hiatus" of global surface warming has been shown to have great impacts on regional climate, such as the reversal of Indian monsoons (Jin and Wang 2017), amplified Arctic warming (McGregor et al. 2014), and extreme weather events (Sillmann et al. 2014). In this study, we identified a significant warming slowdown in the SCS during 1999-2010 (Fig. 1a) based on multiple datasets, whereas most of the Coupled Model Intercomparison Project Phase 5 (CMIP5) models failed to capture this regional warming slowdown. With a set of sensitivity experiments using a high-resolution, regional coupled model, the causes of the SCS sea surface warming slowdown during 1999-2010 are analyzed.

\section{Data and methods}

\subsection{Observational and reanalysis datasets}

SST data products derived from satellite retrievals, observations, and reanalysis are used in this study. Winds and air temperatures at various vertical atmospheric levels are from National Centers for Environmental Prediction (NCEP) reanalysis products and coupled model intercomparison project phase 5 (CMIP5) simulations. The SST datasets are collected from the Simple Ocean Data Assimilation ocean/sea ice reanalysis (SODA) v3.4.2 $\left(0.25^{\circ} \times 0.25^{\circ}\right.$, Carton et al. 2018) and v2.2.4 $\left(0.4^{\circ} \times 0.4^{\circ}\right.$, Carton and Giese 2008), the Hadley Centre Sea Ice and SST data set (HadISST; $1^{\circ} \times 1^{\circ}$, Rayner et al. 2003), and the Extended Reconstructed SST (ERSST) v5 data set $\left(2^{\circ} \times 2^{\circ}\right.$, Smith et al. 2008). SODA is ocean reanalysis data, including various observational datasets with data assimilation methods. HadISST is a global telecommunications system (GTS)-based dataset. ERSST is a global monthly SST analysis from the International Comprehensive Ocean-Atmosphere Dataset, which does not include satellite data. The air temperatures and winds at the $200 \mathrm{hPa}$ and $850 \mathrm{hPa}$ pressure levels are from the NCEP/NCAR Reanalysis $1\left(2.5^{\circ} \times 2.5^{\circ}\right.$, Kalnay et al. 1996). Simulations of SST from 14 CMIP5 simulations with 53 runs are also included (Table 1). The CMIP5 historical runs cover the period of 1970-2002, while for the 2002-2015 period, some historical runs are merged with the so-called RCP4.5 (a medium mitigation scenario called 'Representative Concentration Pathway 4.5') emission scenarios (Taylor et al. 2012). Note that anomaly computation is conducted by removing the SCS basin average, and the decadal trend of ocean and air values is averaged yearly to remove seasonal variability.

\subsection{RegCM-FVCOM coupled model}

The regional air-sea fully coupled model for the SCS was developed and validated in our previous studies (Wei et al. 2013, 2014; Jiang et al. 2019). The model adopts Regional Climate Model version 3 (RegCM3) as the atmospheric component (Pal et al. 2007), which was originally developed at the National Center for Atmospheric Research (NCAR), and the Finite-Volume Coastal Ocean Model (FVCOM) is adopted as the oceanic component (Chen et al. 2003a), which was developed at the University of MassachusettsDartmouth. The atmospheric component adopts the dynamical core based on the hydrostatic version of Pennsylvania State University/NCAR Mesoscale Model Version 5 (MM5) (Grell et al. 1994) and the atmospheric radiative transfer scheme from NCAR's Community Climate Model Version 3 (CCM3) (Kiehl et al. 1996). A bulk aerodynamic ocean flux parameterization scheme is used to compute the ocean surface fluxes (Zeng et al. 1998). The oceanic component, with an unstructured (triangular) grid, solves the momentum and thermodynamic equations with a second-order finitevolume flux scheme, which amalgamates the advantages of finite-element methods for geometric flexibility and finitedifference methods for computational efficiency. Vertical eddy viscosity and diffusivity are resolved by the Mellor and Yamada level 2.5 turbulent closure scheme (Mellor and 
Fig. 1 Sea surface temperature (SST) time series and spatial trends. a Observed and modeled time series of the South China Sea (SCS) SST anomalies $\left({ }^{\circ} \mathrm{C}\right)$. The SST is averaged within an area of $2^{\circ} \mathrm{N}-24^{\circ} \mathrm{N}, 100^{\circ}$ E- $120^{\circ} \mathrm{E}$, as shown in b-d. The SODA re-analysis (black), Hadley observed SST (blue), ERSST (green) are served as reference datasets comparing with RegCM3-FVCOM coupled model (red). The linear decadal trends (denoted by 'rc') and $p$ values are listed in the box located at the upper-left corner in panel a. The dashed black line indicates the trend of SODA. The vertical shading in gray emphasizes the abnormally high SST year of 1998, which was masked out when performing the trends. b, c Spatial distributions of decadal trends calculated using SODA SST $\left({ }^{\circ} \mathrm{C}\right.$ decade $^{-1}$ ) during 1970-1997 and after 1999, respectively. d, e Similar to b, c, but using modeled SST. The black and white dots show the significant trends at $90 \%$ significant level
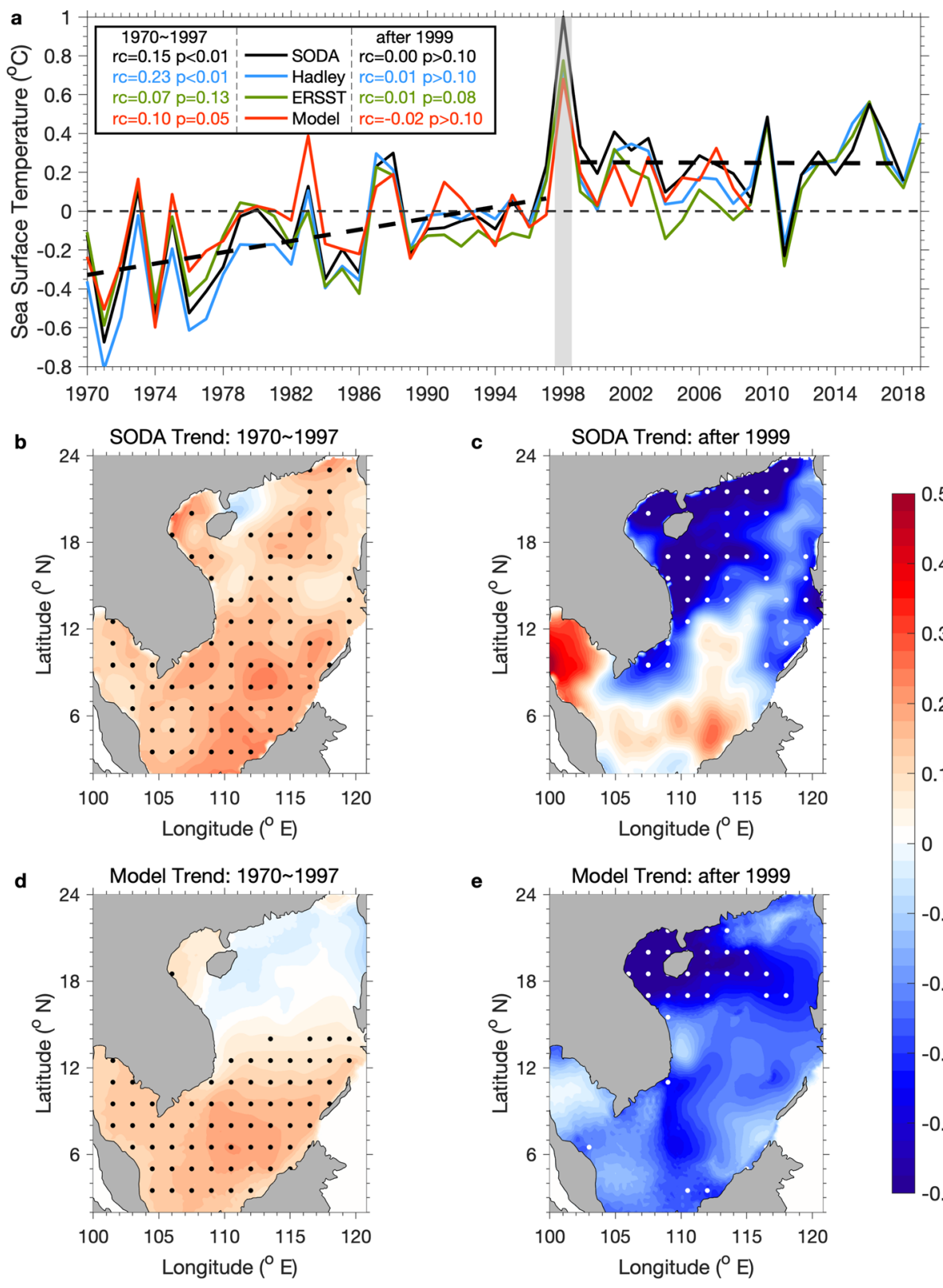

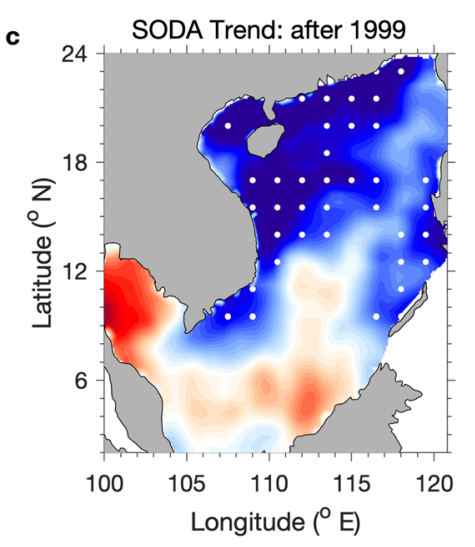

。

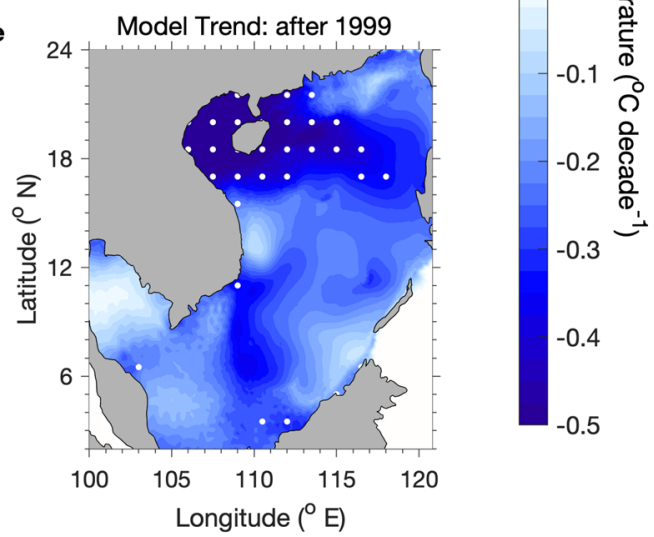

Yamada 1982), and horizontal diffusivity is calculated by the Smagorinsky turbulence closure (Smagorinsky 1963).

The model domains of RegCM3 are set from $85^{\circ} \mathrm{E}$ to $142^{\circ} \mathrm{E}$ and from $20^{\circ} \mathrm{S}$ to $30^{\circ} \mathrm{N}$, which is slightly larger than the FVCOM. This model covers the entire SCS basin, East Asian monsoon area, SCS throughflow (SCSTF) and Indonesian throughflow (ITF). The horizontal resolution of RegCM3 is homogeneously $60 \mathrm{~km}$; however, the resolution of the FVCOM varies from $\sim 5 \mathrm{~km}$ on the shelves, continental slopes and narrow straits to $\sim 50 \mathrm{~km}$ within the deep SCS and $200 \mathrm{~km}$ along the ocean open boundaries. The ERA-40 dataset from the European Centre for Medium-Range Weather Forecasts (ECMWF) (Uppala et al. 2005) offers the initial and boundary conditions for RegCM3, and the SODA reanalysis product provides the FVCOM model inputs. After a 10-year spin-up during the 1960s, RegCM3 and FVCOM were simultaneously integrated forward from 1970 to 2010 through an OASIS3 coupler, which allowed flexible interpolation and transfer of the coupling fields (winds, heat fluxes and SST) between different grids every $3 \mathrm{~h}$. More detailed model setup and validations can be found in our previous study (Wei et al. 2013). Moreover, the FVCOM-only model is validated against in situ datasets (Xu et al. 2013), and the local air-sea feedback mechanisms with a fully coupled version are also verified in Xue et al. (2014). 


\subsection{Partial-coupling experiments}

To identify the driving factors, the decomposition method with partial-coupling $(\mathrm{P}-\mathrm{C})$ experiments was used, following our previous study (Wei et al. 2016a). P-C experiments allow for partial air-sea coupling by controlling either atmospheric or oceanic variables and are widely used in global GCMs (Ding et al. 2014a; Wu et al. 2003; Zhong et al. 2008). The difference between the control run (CTL) and $\mathrm{P}-\mathrm{C}$ experiments decomposes the effect of the controlled variables. To separate the different roles induced by atmospheric effects and boundary intrusion effects on the SCS, a set of experiments are carried out. The fully coupled model integrated from 1970 to 2010 is referred to as the control run (CTL).

In the temperature tendency equation (Eq. 1), intrusion, mainly dominated by the variability in the Luzon Strait intrusion, can be estimated by $C T L-F B C$. For simplicity, here, we use FSC and FBC to represent $C T L-F S C$ and $C T L-F B C$, respectively.

\section{The remarkable warming slowdown in the SCS}

\subsection{Warming slowdown in observations}

Based on the global reanalysis datasets, Fig. 1a shows that the SCS SST experienced an accelerated and unprecedented warming trend $\left(+0.15^{\circ} \mathrm{C}\right.$ decade $\left.^{-1}, p<0.01\right)$ during 1970-1997. A strong warming trend is detected over

$\frac{\partial T}{\partial t}=-\left(u \frac{\partial T}{\partial x}+v \frac{\partial T}{\partial y}+w \frac{\partial T}{\partial z}\right)+\frac{\partial}{\partial x}\left(A_{h} \frac{\partial T}{\partial x}\right)+\frac{\partial}{\partial y}\left(A_{h} \frac{\partial T}{\partial y}\right)+\frac{\partial}{\partial z}\left(K_{h} \frac{\partial T}{\partial z}\right)+\frac{Q}{h \rho_{0} C_{p}}$,

where the left-hand side is the temperature change rate; $u, v$ and $w$ are the ocean current velocities; $A_{h}$ and $K_{h}$ are the horizontal and vertical diffusion coefficients; and $h, C_{p}$, and $\rho_{0}$ are the mixed-layer depth, water density and specific heat of water, respectively. Therefore, the temperature change is controlled by advection, horizontal and vertical diffusion, and heat flux terms. However, advection and heat flux terms always dominate near the surface mixing layer (Jiang et al. 2018; Uhlhorn and Shay 2013; Wei et al. 2016a), occupying up to $96 \%$ of the total change over the whole SCS (see details in Wei et al. 2016a), but the vertical mixing term can be significant at the subsurface, e.g., the thermocline, where the vertical temperature gradient is much larger. Regional climate processes mostly involve boundarycontrol issues, as are the experiments designed in this study. To separate the effects of atmospheric and oceanic forcing on the SCS SST variance, in the "fixed surface condition" (FSC) experiment, the lateral conditions of the air model (heat fluxes and winds) for 1980-2010 are prescribed repeatedly using the lateral conditions of 1970-1980. Similarly, in the "fixed boundary condition" (FBC) experiment, the lateral boundary conditions of the ocean model (temperature, salinity and transport) are prescribed repeatedly using the boundary conditions of 1970-1980. Apart from the lateral conditions, other settings are kept the same as in the CTL. Thus, the difference between CTL and FSC identifies the SST variance due to the atmospheric surface forcing, and CTL-FSC identifies the SST variance due to oceanic advection.

As a result, the forcing of surface atmospheric effects can be estimated by $C T L-F S C$; the effects of boundary the whole SCS area, from coastal margins to the central realm (Fig. 1b). However, this sea surface warming trend encountered a significant slowdown during 1999-2010, with an overall rate of $-0.01{ }^{\circ} \mathrm{C}$ decade $^{-1}(p>0.10)$, and continued to flatten even into 2019. The most remarkable warming slowdown occurs in the northern SCS, with a cooling rate of $-0.5^{\circ} \mathrm{C}$ decade $^{-1}$ (Fig. $1 \mathrm{c}, p<0.10$ ).

To demonstrate that the sea surface warming slowdown marks a decadal feature, an 18-year running mean of SST trends is carried out (Fig. 2). The recalculated SST trends clearly demonstrate that the SCS SST continues to rise during the period of 1970-1990. However, the sea surface warming rate drops from above $0.1{ }^{\circ} \mathrm{C}$ decade $^{-1}$ to below zero after 1990 and is persistent in the following years in the SODA, HadISST and ERSST data.

Further analysis on a seasonal timescale based on HadISST shows that the warming slowdown of the SCS sea surface after 1999 is much stronger during boreal winter (drops from 0.25 to $-0.08{ }^{\circ} \mathrm{C}$ decade $^{-1}, p<0.10$ ), followed by spring (drops from 0.20 to $-0.03{ }^{\circ} \mathrm{C}$ decade $^{-1}$, $p<0.15$ ) and summer with a slight slowdown trend, as shown in Fig. 3a. The spatial pattern shows that during 1970-1997 the SCS warming trend is nearly uniform over the entire SCS in the four seasons, while the warm slowdown during 1999-2015 occurs mainly in the northern SCS in the winter and spring seasons. The largest cooling rate along the northern SCS shelf follows the path of the SCS through from the Luzon Strait to the Vietnam coast. Note that this cooling rate along the northern SCS shelf is significantly weakened in the summer and disappeared in the autumn. 
Fig. 2 SST trends calculated using an 18-year moving window. The linear trends $\left({ }^{\circ} \mathrm{C}\right.$ decade $^{-1}$ ) are computed based on the SCS SST time series in Fig. 1a. The significant trends at the $90 \%$ significant level are marked with 'square' symbols

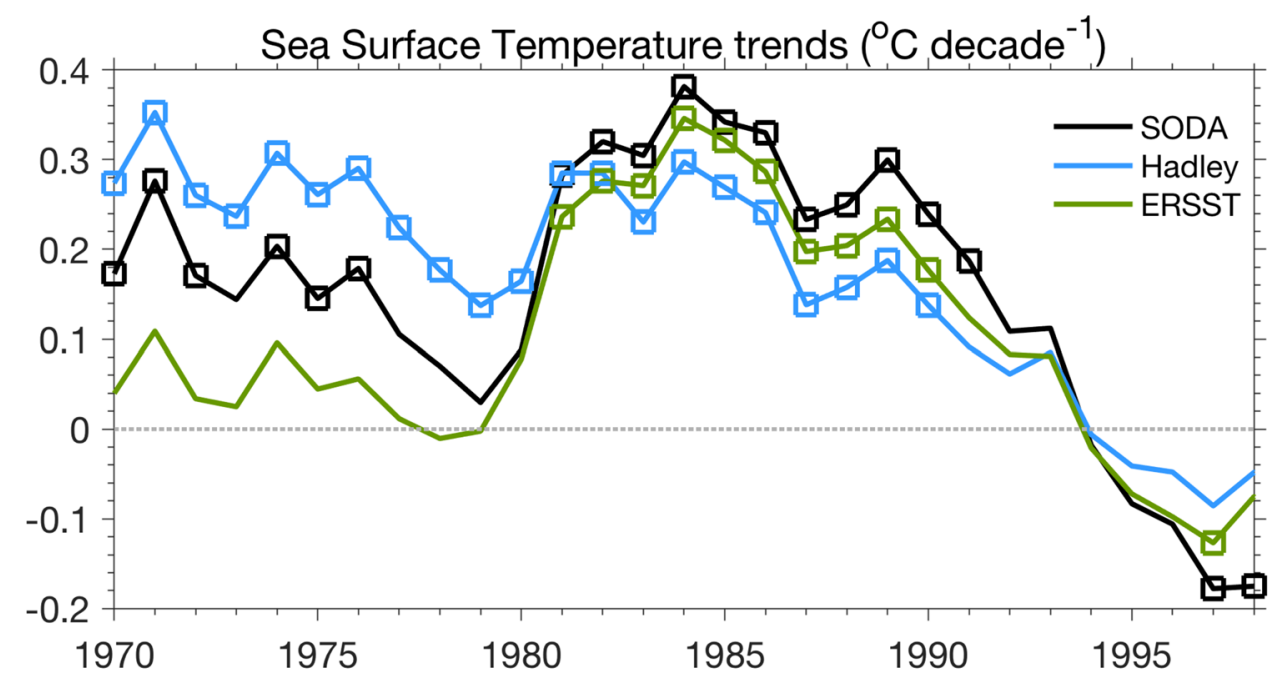

\subsection{Warming slowdown in models}

Given the complex topography of the SCS and its multiple narrow passages to the open western Pacific, global climate models of CMIP5 are usually unable to accurately resolve physical processes in this region due to their coarse resolutions, which could be one of the reasons that most CMIP5 models fail to simulate the SCS SST. To include the local effects from topography, coastlines and islands, we adopted a high-resolution RegCM-FVCOM coupled model. The remarkable warming slowdown in the SCS is reproduced well by the model, with a mean absolute error (MAE) of $0.12{ }^{\circ} \mathrm{C}$ and correlation coefficient of 0.90 with observational products (see red line in Fig. 1a). Specifically, compared with the SODA data, the coupled model captures the warming trend in the central and southern SCS well from 1970 to 1997 (Fig. 1b, d) and the cooling trend in the northern SCS during 1999-2010. (Fig. 1c, e).

\section{Identifying the drivers of the SCS warming slowdown}

\subsection{Partial-coupling experiments}

Previous studies have shown that the semi-closed SCS climate system is largely driven by the variability in East Asia monsoons and Luzon Strait intrusions (Gordon et al. 2012; Klein et al. 1999; Wei et al. 2016a). Therefore, a set of partially coupled experiments are carried out to investigate the contribution of monsoon winds and Luzon Strait transport to the warming slowdown in the SCS. The experiment details are shown in Sect. 2.3.
The two P-C experiments were carried out, and the results are shown in Fig. 4. The total variations in the SCS SST can generally be represented by the two components, explaining over $87 \%$ of the total variance (Fig. 4a). The decomposed components show that the change in air surface conditions (CTL-FSC) dominated the remarkable warming slowdown of the SCS, accounting for $75 \%$ of the total variance $\left(-0.17{ }^{\circ} \mathrm{C} \mathrm{decade}^{-1}, p<0.10\right)$ during $1999-2010$. This result indicates that the SCS warming slowdown is largely attributed to the enhanced monsoons. On the other hand, the SST changes induced by ocean boundary conditions (CTL-FBC) account for $12 \%$ of the total variance. The residual ( $\sim 13 \%$ of the total variance) may come from the nonlinear vertical mixing and vertical advection of ocean subsurface, which cannot be linearly decomposed. Note that the $\triangle S S T$ shown in Fig. $4 \mathrm{a}, \mathrm{b}$ is calculated as follows:

Total $\Delta$ SST $=C T L(1980 s, 1990 s, 2000 s)-C T L(1970 s)$;

$\Delta$ SST due to air surface forcing $=C T L(1980-2010)-F S C(1980-2010)$,

$\Delta$ SST due to oceanic boundary $=C T L(1980-2010)-F B C(1980-2010)$.

\subsection{Attribution of SCS warming slowdown}

Figure $4 \mathrm{~b}$ shows that the sea surface warming slowdown over the SCS in the FSC experiment is much stronger in boreal winter $\left(-0.33{ }^{\circ} \mathrm{C}\right.$ decade $\left.^{-1}, p<0.10\right)$ than in summer $\left(-0.09{ }^{\circ} \mathrm{C}\right.$ decade $\left.^{-1}, p>0.10\right)$. The variability in the warming slowdown trends in the boreal winter and summer seasons is consistent with the observational products (Fig. 3a). For the direct cause of the warming slowdown in the FSC experiment, the net heat flux absorbed by the ocean experienced a rapid decrease $\left(-10.8 \mathrm{~W} \mathrm{~m}^{-2}\right.$ 


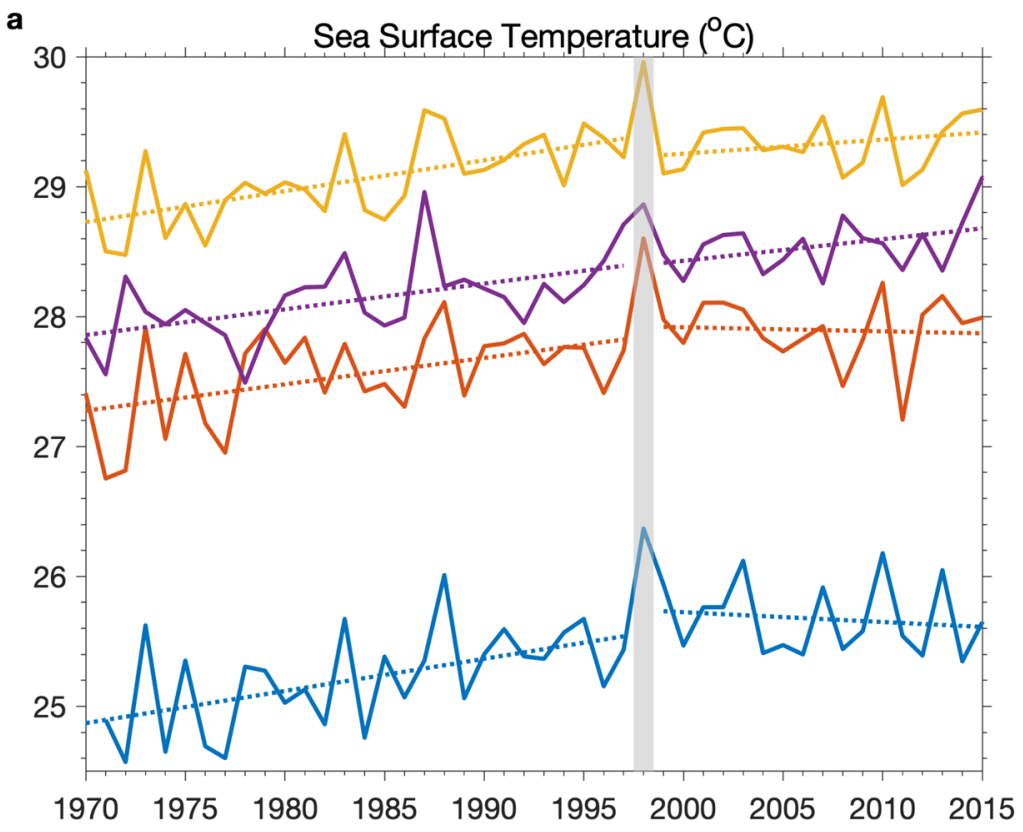

b
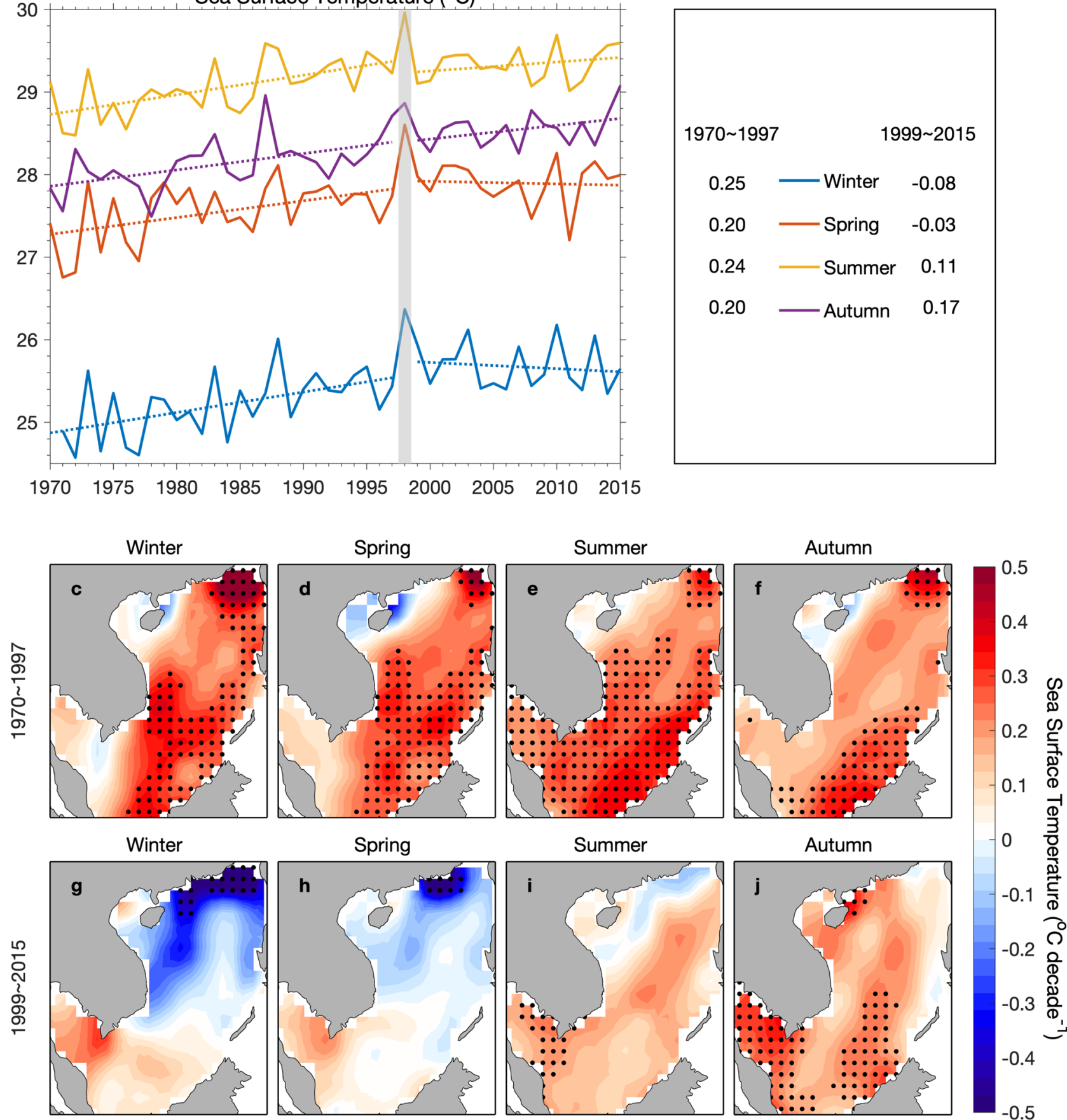

Fig. 3 SST time series and spatial trends of each season. a SCS SST $\left({ }^{\circ} \mathrm{C}\right)$ time series of boreal winter (purple), spring (blue), summer (orange) and autumn (yellow). The SST data used here comes from HadISST, similar with the results of ERSST, OISST and SODA reanalysis. The vertical shading in gray is similar with that in Fig. 1. b
The SCS SST trends $\left({ }^{\circ} \mathrm{C}\right.$ decade $\left.{ }^{-1}\right)$ of each season during 1970-1997 and 1999-2015. $\mathbf{c}-\mathbf{j}$ The spatial pattern of decadal SST trends of each season during 1970-1997 and 1999-2015 respectively. The black dots indicate the $90 \%$ significant level decade $^{-1}, p<0.10$ ) during 1999-2010 (Fig. 5c). The majority of the net heat flux decrease originates from the accelerated latent heat uptake from the ocean surface $(r$
$=-0.94 ; p<0.01)$, from a negative rate of $-0.7 \mathrm{~W} \mathrm{~m}^{-2}$ decade $^{-1}(p<0.10)$ during $1970-1997$ to a positive rate of $8.2 \mathrm{~W} \mathrm{~m}^{-2}$ decade $^{-1}$ during 1999-2010 $(p<0.10$, 
Fig. 4 Time series and spatial trends of modeled SST and surface wind. a Time series of SCS SST difference $\left({ }^{\circ} \mathrm{C}\right.$, averaged within the same SCS area as Fig. 1a) in simulations of CTL (black line), fix surface condition experiment (FSC, red line) and fix boundary condition (FBC, blue line). The percentages in legends are contribution to CTL calculated based on ' $r c_{F S C} / r c_{C T L}$ ' and ' $r c_{F B C} / r c_{C T L}$ '. b Time series of SST difference $\left({ }^{\circ} \mathrm{C}\right)$ in $\mathrm{FSC}$ experiment during boreal summer (JJA, red solid line) and boreal winter (DJF, red dashed line) using the left $y$-axes, and surface absolute wind speed $\left(\mathrm{ms}^{-1}\right)$ abnormally of boreal winter (green solid line) using the right $y$-axes (larger values mean stronger southward winter monsoon). $\mathbf{c}, \mathbf{d}$ The spatial distribution of FSC decadal SST trends $\left({ }^{\circ} \mathrm{C}\right.$ decade-1, shading) and decadal surface wind abnormally trends $\left(\mathrm{ms}^{-1}\right.$ decade $^{-1}$, green arrows) of boreal winter during 1980-1997 and after 1999 respectively. e, f, Similar to c-d, but for FBC experiment in boreal winter (the green arrows indicate the current trends on the ocean surface). The black dots indicate the trends at $90 \%$ significant level. More details of $\triangle S S T$ calculation in $\mathbf{a}, \mathbf{b}$ are shown in Sect. 2.3

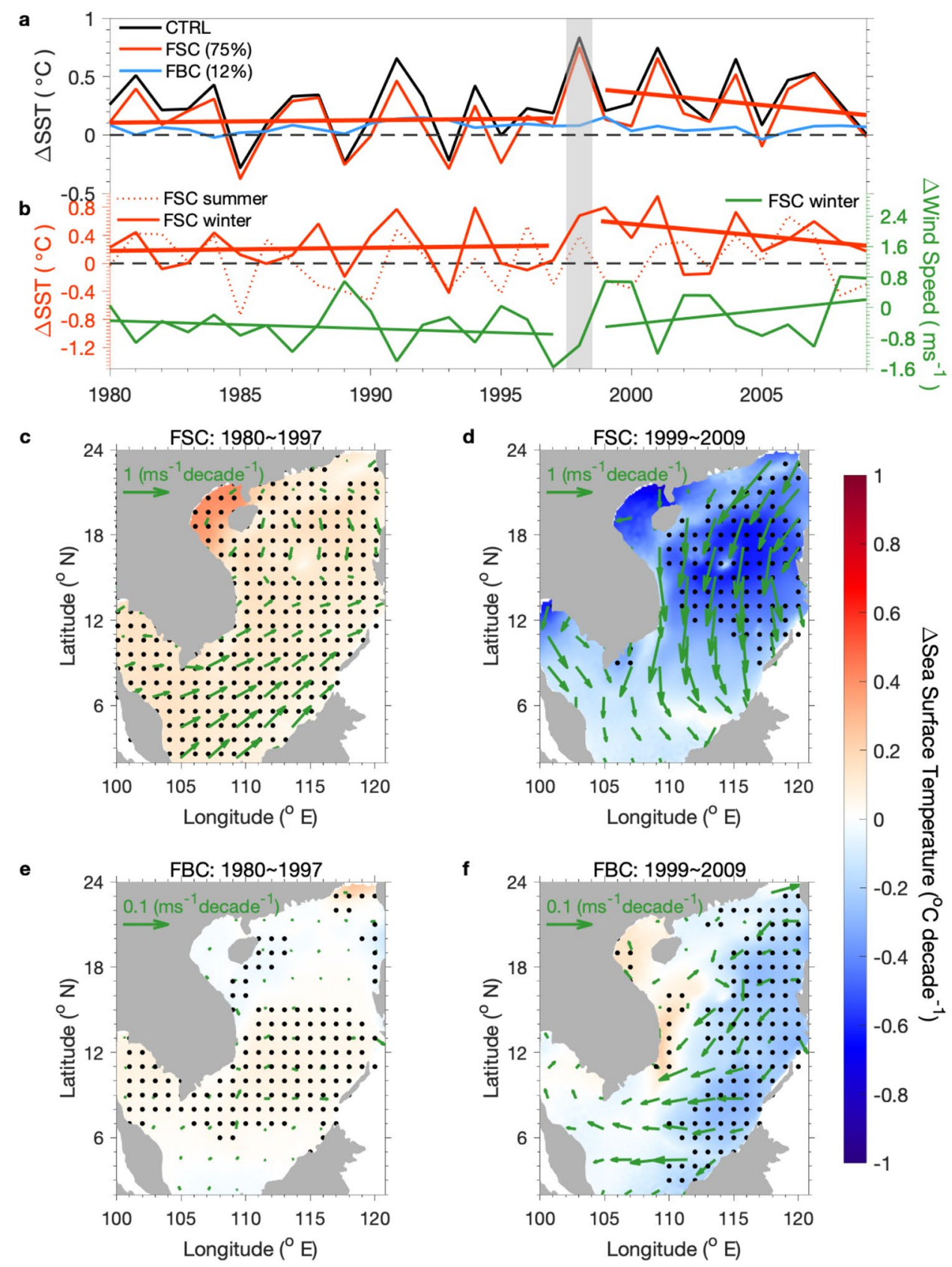

Fig. 5b). The accelerated evaporation (latent heat uptake) is closely related to the revival of the modeled East Asian winter monsoon (EAWM), from a negative rate of $-0.21 \mathrm{~ms}^{-1} \mathrm{decade}^{-1}(p<0.10)$ before 1999 to a positive rate of $0.71 \mathrm{~ms}^{-1}$ decade $^{-1}$ after $1999(p<0.10$, Fig. $4 \mathrm{~b})$. Such a revival of the modeled EAWM is consistent with the National Centers for Environmental Prediction (NCEP) reanalysis products (Fig. 6). Therefore, the warming slowdown trend in boreal winter is obviously attributed to the revival of the EAWM ( $r=-0.49, p<0.01$, Fig. $4 b)$.

The spatial distribution of the SST trend over the SCS in the FSC experiment shows a basin-wide homogenous warming rate of $0.14{ }^{\circ} \mathrm{C}$ decade $^{-1}(p<0.01$, Fig. $4 \mathrm{c})$, which is coincident with the weakened EAWM over the SCS from 1980 to 1997 (Fig. 4b, green line). However, after 1999, the enhanced EAWM resulted in strong sea surface cooling 
Fig. 5 Time series of $\Delta S S T$ and heat flux. a Same as Fig. 4a, but for SST abnormally of FSC + FBC experiments versus CTRL. The black line uses the left y-axes while the red line uses the right y-axes. b, c Same as Fig. 4b, but for latent heat flux and net heat flux $\left(\mathrm{W} \mathrm{m}^{-2}\right)$ respectively. The red dashed line is for boreal summer and green solid line is for boreal winter

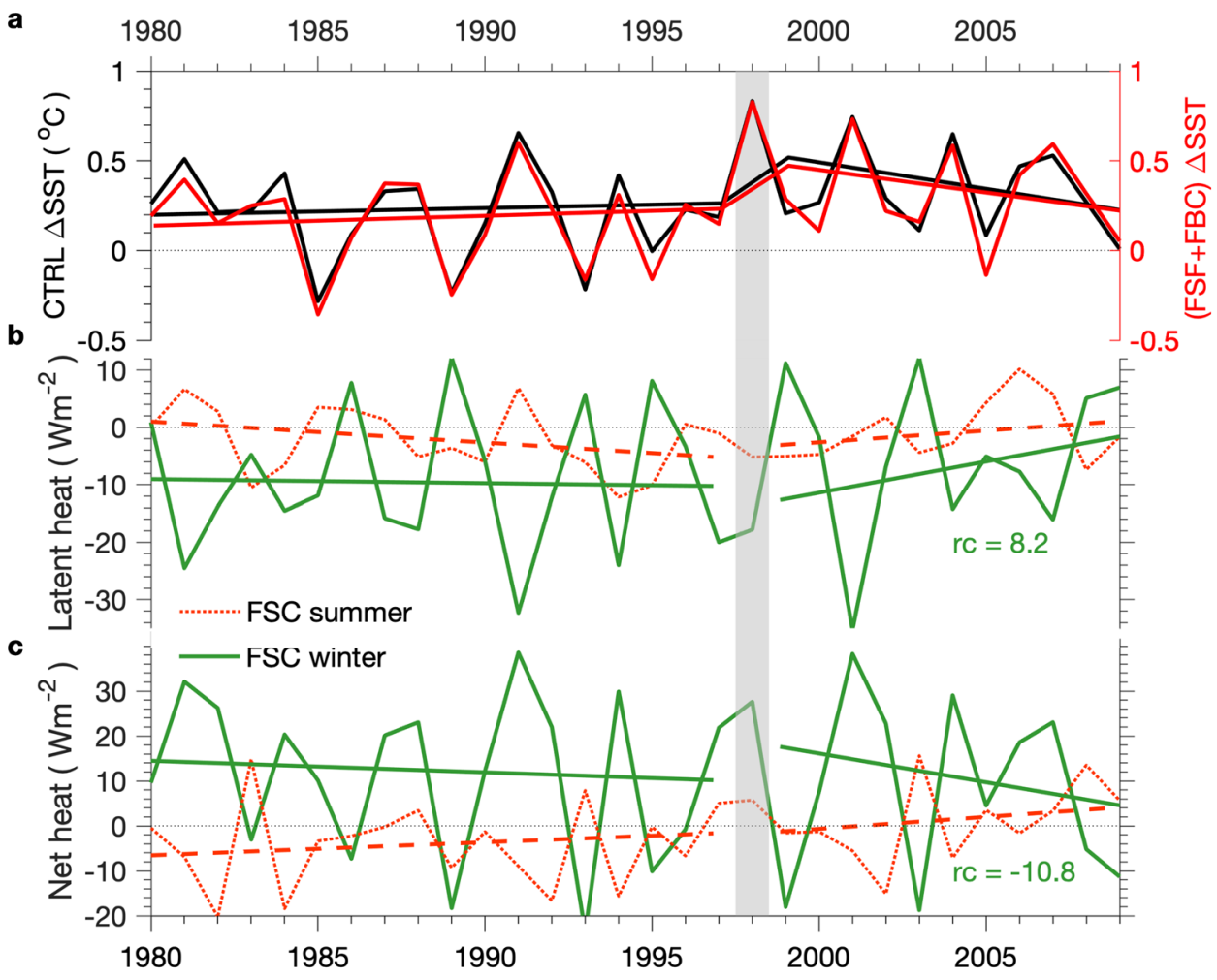

over the entire SCS (Fig. 4d). This result confirms that the EAWM shifting before and after 1999 is the major forcing on the SCS SST, accounting for $75 \%$ of the SST variance and influencing the entire SCS basin. On the other hand, the effect of oceanic boundary forcing on the SCS SST is small compared to the EAWM effect, but obviously larger than its effect during 1980-1997 (Fig. 4e, f). As demonstrated in many previous studies, the SCS throughflow via the Luzon Strait strengthened after 1999 when the climate system shifts from positive PDO with more El niño events to negative PDO with more La Niña events (Qiu and Lukas 1996; Kim et al. 2004; Qiu and Chen 2010; Gordon et al. 2014). Our previous study also confirmed the strengthened SCSTF by decomposing the sea surface height (Wei et al. 2016a, b), which drives more cool water from the northern SCS to the central and southern regions.

To reveal the mechanism of the enhanced EAWM, Fig. 7shows the spatial trends of surface winds and heat fluxes in the SCS, and Fig. 8 indicates the linkage of the SCS domain to the Pacific. The results demonstrate that the SCS SST is positively correlated with the SST over the eastern tropical Pacific (Fig. 8), implying that the SCS warming slowdown can likely be linked to the eastern tropical Pacific. Based on the NCEP atmospheric analysis data, Niña-like sea surface cooling in the eastern tropical Pacific results in convection and an anticyclonic anomaly in the western Pacific in the lower atmosphere (Fig. 8b). This phenomenon has been documented in previous studies (Ding et al. 2014b; Liu et al. 2011; Wang et al. 2000). The anticyclonic air circulation anomaly further enhances the EAWM over the SCS (Fig. 7e). In contrast, the SCS sea surface experiences nonsignificant cooling during the boreal summer (Fig. 7a-d), with a pattern balanced by the opposite phase of the net heat flux trend. This result can be explained by a negative feedback that the cold (warm) SST forces less (more) evaporation and thus less (more) highly reflective cirrus clouds form, and consequently, more (less) shortwave radiation reaches the ocean surface (Ramanathan and Collins 1991). This feedback weakens as the Northern Hemisphere enters the boreal winter season, in which the SCS SST is mainly controlled by the revived EAWM. 

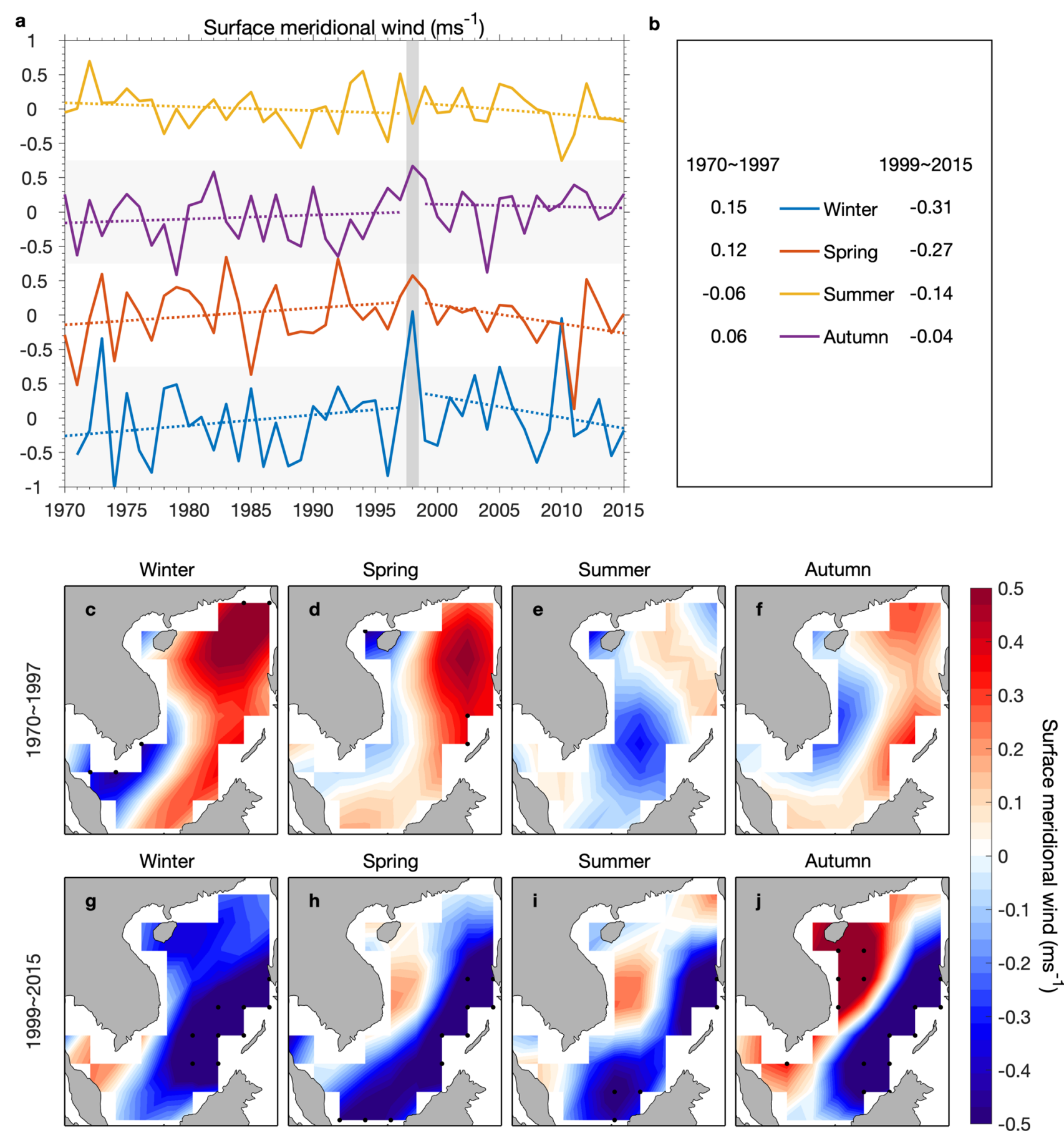

Fig. 6 The same as Fig. 3, but for surface meridional wind speed abnormally from NCEP dataset. The positive trends mean northward monsoon while negative trends mean southward (e.g. negative trends in winter mean stronger winter monsoon)

\section{Summary and discussion}

A significant slowdown in the SCS warming rate during 1999-2010 is observed in both remote-sensed satellitederived products and reanalysis datasets (Fig. 1), following a long-term warming trend from 1970 to 1997 . However, most of the IPCC CMIP5 climate models failed to reproduce this warming slowdown in the SCS. Based on a highresolution regional air-sea coupled model with a set of $\mathrm{P}-\mathrm{C}$ 

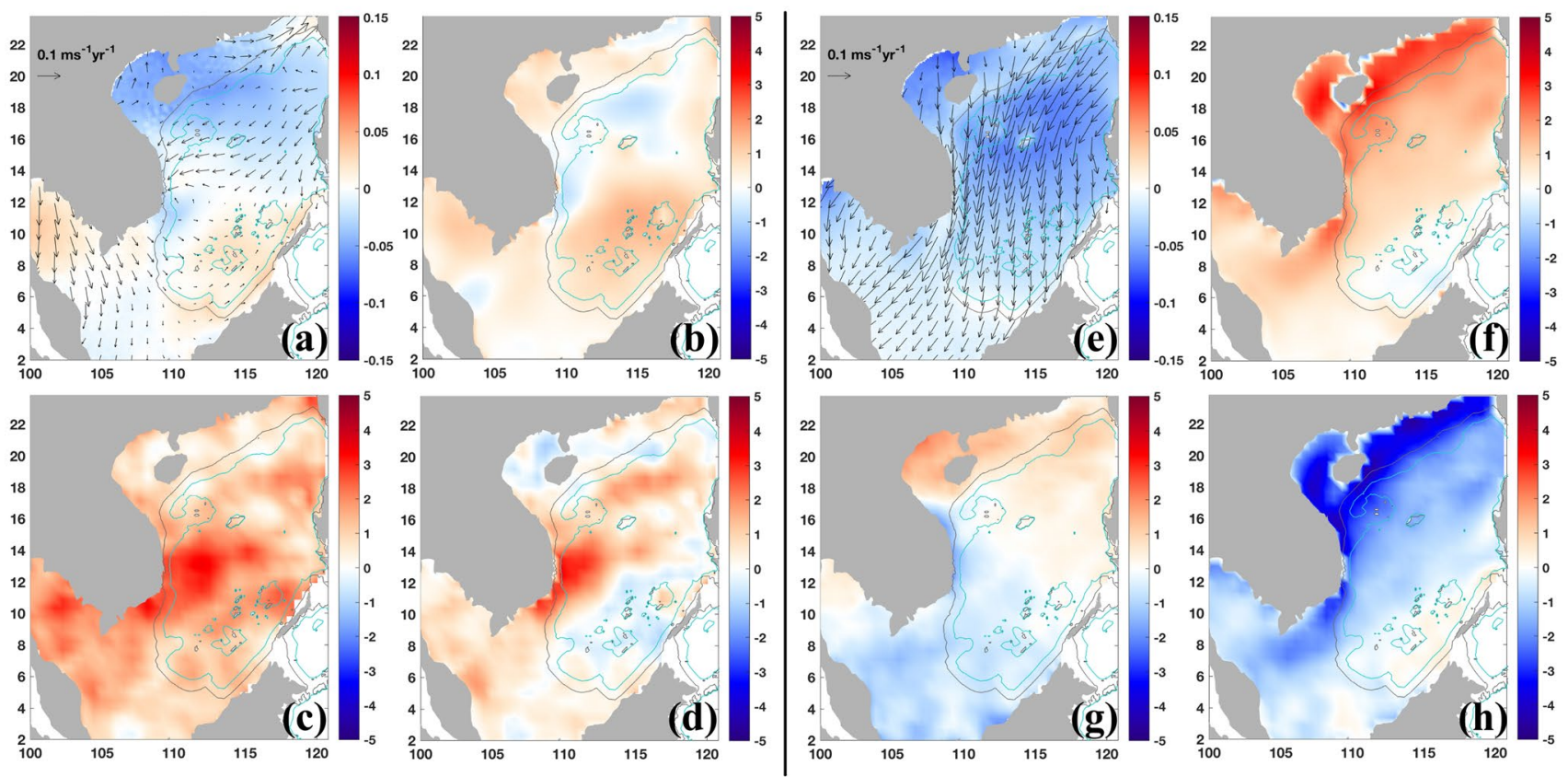

Fig. 7 Spatial trends of wind, heat flux and SST in FSC. a-d Decadal spatial trends of SST versus surface wind (a), latent heat flux uptake (b), short wave heat flux absorbed (c) and net heat flux absorbed (d) during boreal summer, respectively. $\mathbf{e}-\mathbf{h}$ The same as a-d, but for boreal winter

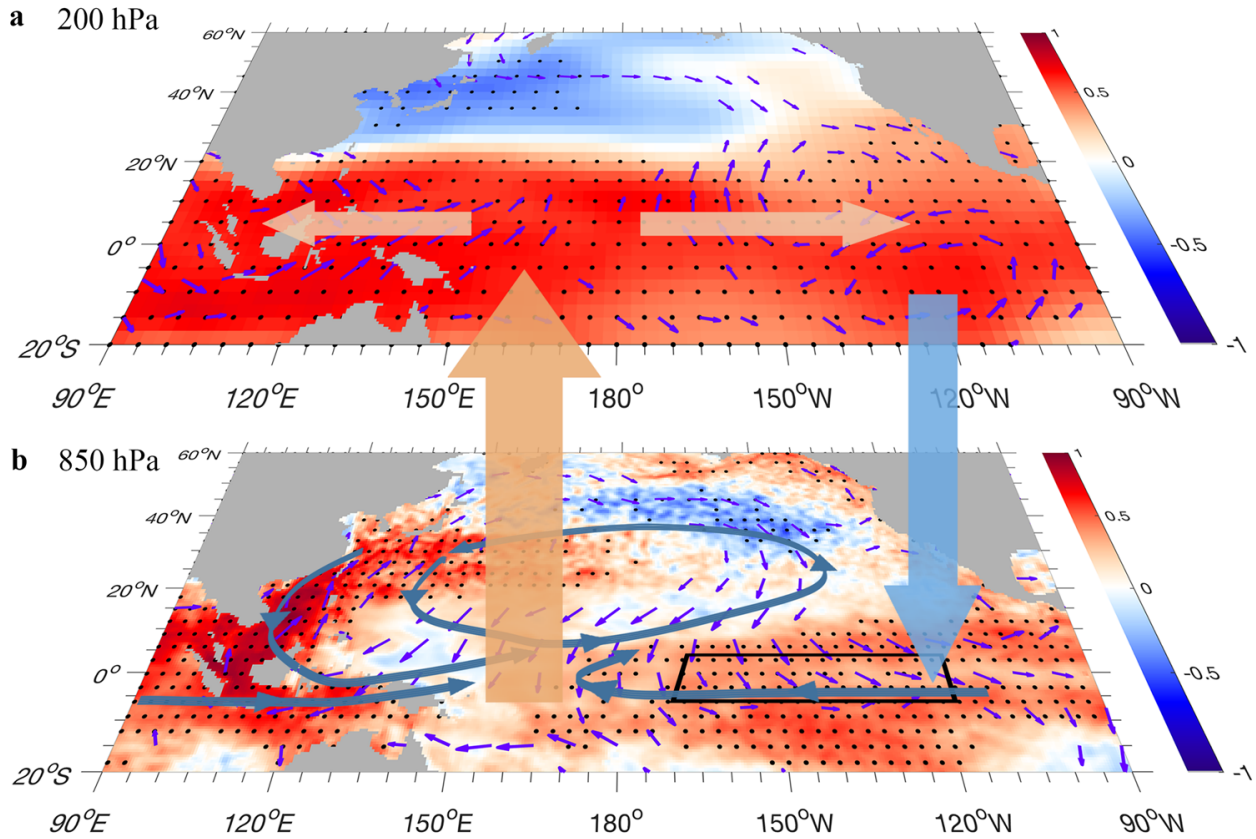

Fig. 8 Correlations between SCS SST and Pacific temperature and wind. a Correlation coefficients between SCS SST and NCEP air temperature (shading) and wind vectors (purple arrows) at $200 \mathrm{hPa}$ over Pacific Ocean during boreal winter (DJF) of 1970-2015. b Similar with a, but for the wind vectors at $850 \mathrm{hPa}$ and SODA SST. HadISST and ERSST indicate the same pattern and are not shown here.
The Walker Circulation is highlighted with bigger orange and light blue vectors. The dark blue curves with arrows in $\mathbf{b}$ indicate the circulation trends at $850 \mathrm{hPa}$ during 1999-2015. The black dots indicate the significant correlation with temperature at the $95 \%$ level. Those insignificant correlation coefficient with wind vectors are omitted 
Fig. 9 Time series and spatial distribution of eastern Tropical Pacific SST. a Observational time series of eastern Tropical Pacific SST anomalies $\left({ }^{\circ} \mathrm{C}\right)$ during boreal winter from SODA (black), HadISST (blue) and ERSST (green). Note that the SST is averaged within the same area of nino3.4 $\left(5^{\circ} \mathrm{N}\right.$ to $5^{\circ} \mathrm{S}$, $170^{\circ} \mathrm{W}$ to $120^{\circ} \mathrm{W}$ ). The linear decadal trend of SODA is plotted as black solid line (regression coefficients denoted by ' $r c$ ' below the lines). As a reference, the extension of the warming trend is plotted as black dashed line after 1997. b The distribution of the composite DJF-mean SST anomalies of HadISST during 1999-2015 (similar results exist in SODA and ERSST, not shown here). The bigger arrows are the same as those in Fig. 8

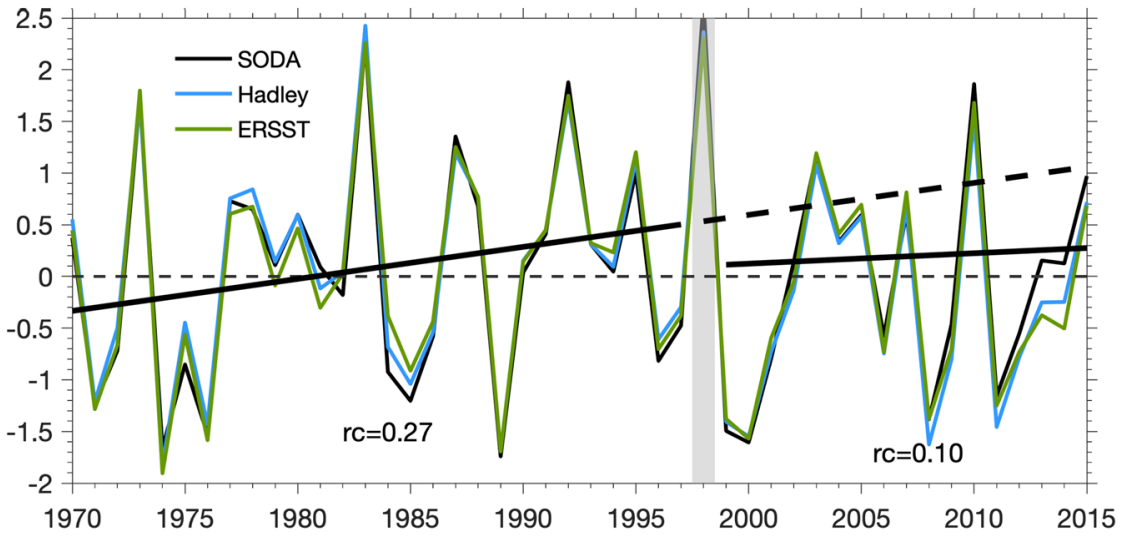

b

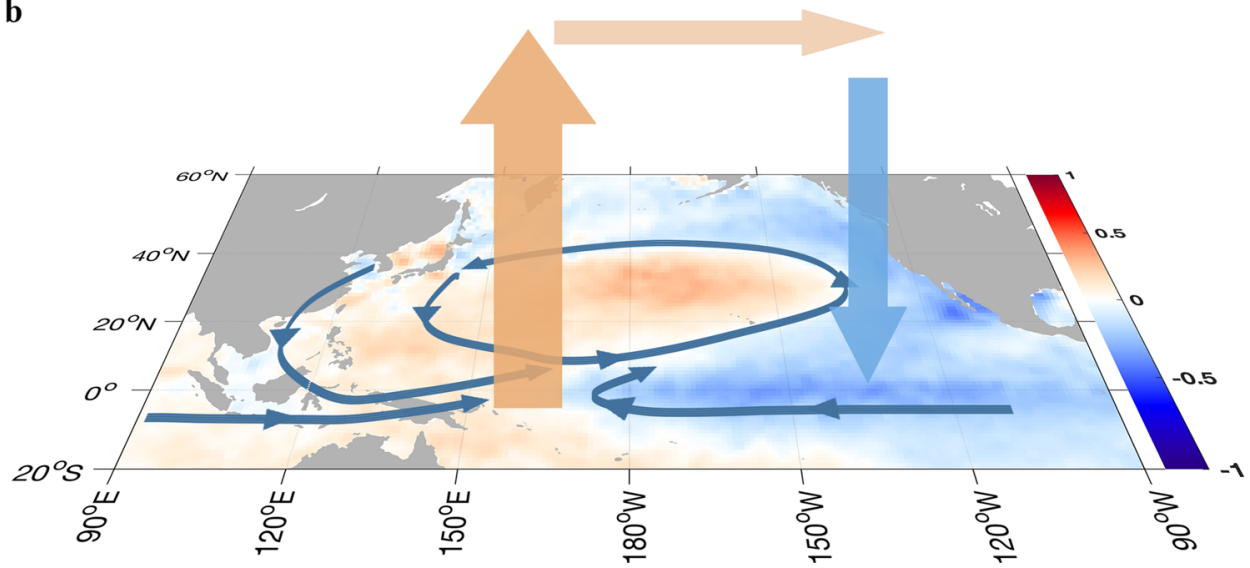

experiments, the model results show that this SCS warming slowdown has the largest magnitude in boreal winter and spring, forced by strengthened EAWM winds during 1999-2010 and thus increased latent heat uptake over the SCS (Figs. 4, 5). The strengthened EAWM may be linked to the La Niña-like SST pattern in the eastern tropical Pacific, which was not simulated by those CMIP5 models. The largest reduction in the SCS warming rate can be attributed to the oceanic throughflow by the Luzon Strait, where most of the CMIP5 models are unable to resolve the local topography and coastlines, as well as the Luzon Strait throughflow.

Increasing local resolution has been adopted in regional models to improve model simulations in the SCS and surrounding oceans and seas (Wei et al. 2013; Lin et al. 2011a, b; Liu et al. 2011; Van Sebille et al. 2014; Tranchant et al. 2016; Li et al. 2019; Jiang et al. 2019; Xue et al., 2014). However, less attention has been given to the linkage of the SCS to large-scale remote forcing through atmospheric bridges. Figure 8 demonstrates that the SCS SST is positively correlated with the SST over the eastern tropical Pacific and positively correlated with the anticyclonic circulation at $850 \mathrm{hPa}$ in the northwestern Pacific during boreal winter. The warming trend of the SCS sea surface during 1970-1997 was captured well by most CMIP5 models when the El Niño-like SST pattern was dominant in the eastern tropical Pacific. However, an obvious warming slowdown occurred over the eastern tropical Pacific during 1999-2015, resulting in cyclonic circulation at $850 \mathrm{hPa}$ in the northwest 
Fig. 10 SCS SST time series and spatial trends of CMIP5 simulations. a SCS SST Time series of CMIP5 RCP45 ensemble mean (blue solid line) and RCP85 ensemble mean (red dashed line). The blue shaded area represents one standard deviation of 53 ensembles of RCP45. The linear decadal trends (denoted by ' $r c$ ') are listed in the box located at northwest side. All $p$ values are less than 0.01 . Note that most of RCP85 EM is overlapped by RCP45 EM before 2005. b, c Spatial pattern of decadal SST trends of CMIP5 RCP45 ensemble mean during 1970-1997 and 1999-2015 respectively, similar in RCP85. The black dots show the $99 \%$ significant level
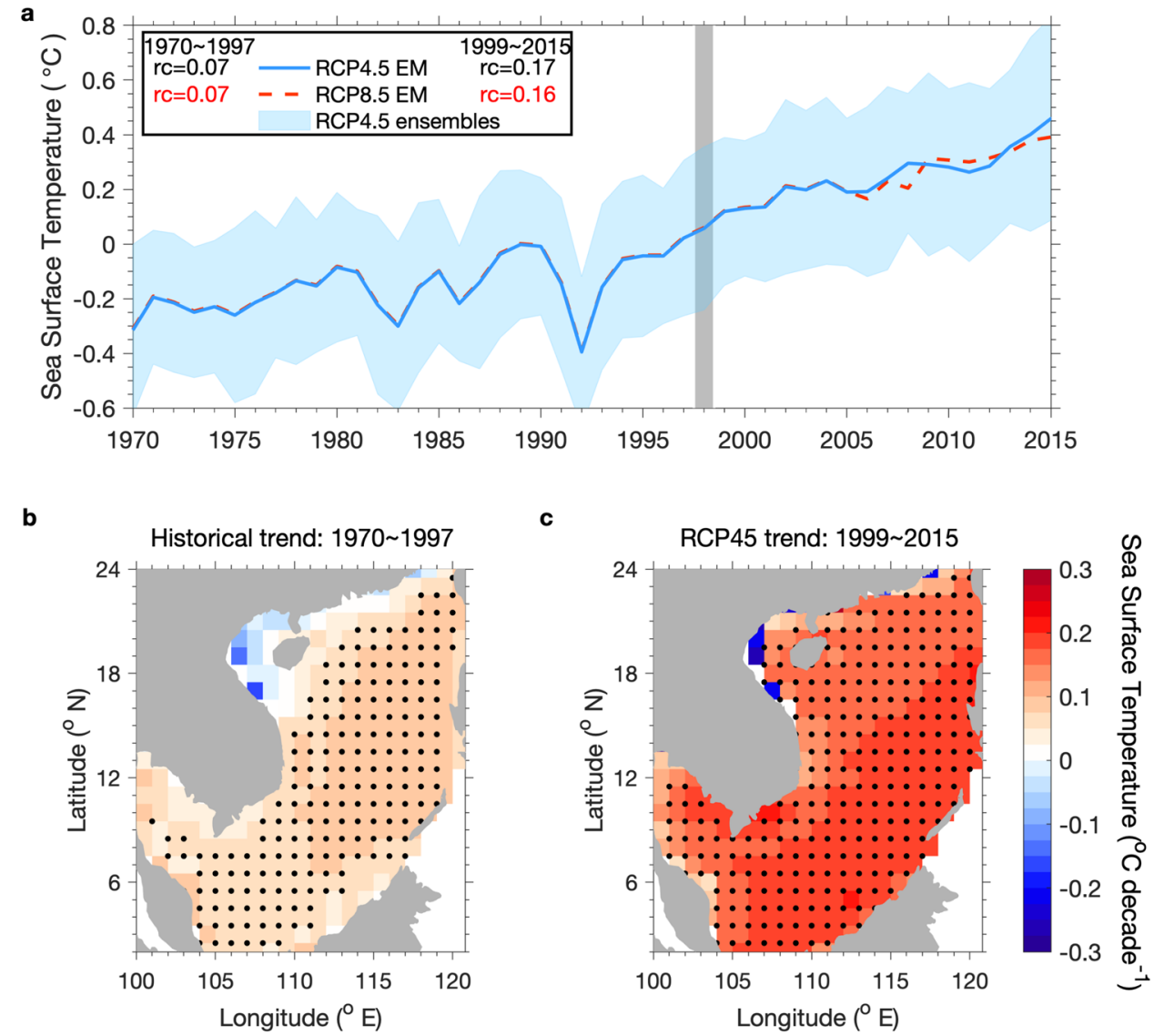

Pacific during boreal winter (Fig. 9), which was not resolved by most of the CMIP5 models. Specifically, 43 out of 53 models were able to capture the warming during 1970-1997 (Fig. 11a); however, more than 40 models failed to simulate the observed warming slowdown in the SCS sea surface during 1999-2015 under the RCP4.5 scenario (Figs. 10, 11b).

The importance of the La Niña-like SST pattern in the eastern tropical Pacific during 1999-2010 was pointed out by Kosaka and Xie (2013), and then they successfully reproduced the so-called global "hiatus" phenomenon by artificially prescribing a cool SST tongue in the eastern tropical Pacific in a GCM. Compared to the remote atmospheric forcing, the effect of the oceanic circulation changes due to the Luzon Strait intrusion is rather small, accounting for $12 \%$ of the total SST variance. One of the reasons is that the SCS throughflow transport is about $4-6 \mathrm{~Sv}$, with local effect within the northern SCS shelf (Wei et al. 2016a). On the other hand, the SCS general circulation is anticyclonic as an oceanic response to the monsoon winds. The SCS throughflow is strengthened not only by the Luzon Strait intrusions, but also the enhanced EAWM. As shown in Fig. 4, the cooling rate on the northern SCS shelf due to the wind effect in the FSC run (Fig. 4d) is even larger than the oceanic boundary forcing in the FBC run (Fig. 4f). This finding indicates that for a regional model, increasing local ocean model resolution may help to better resolve the regional spatial patterns through improved bathymetry oceanic pathways, while improving large-scale atmospheric and oceanic boundary forcing can help to control the model long-term trend by linking local processes to large-scale remote forcings. 

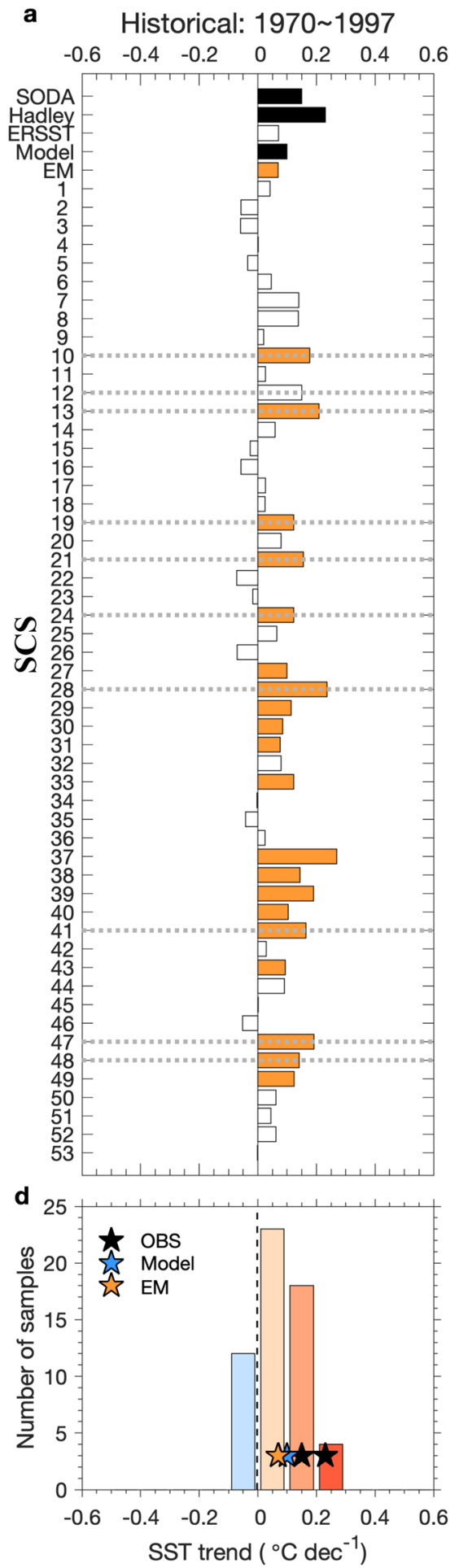

b
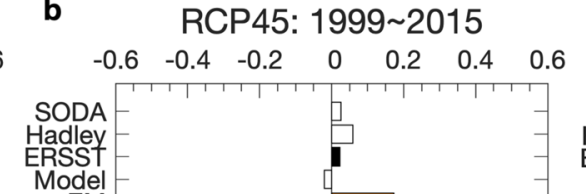

RCP45: 1999 2015
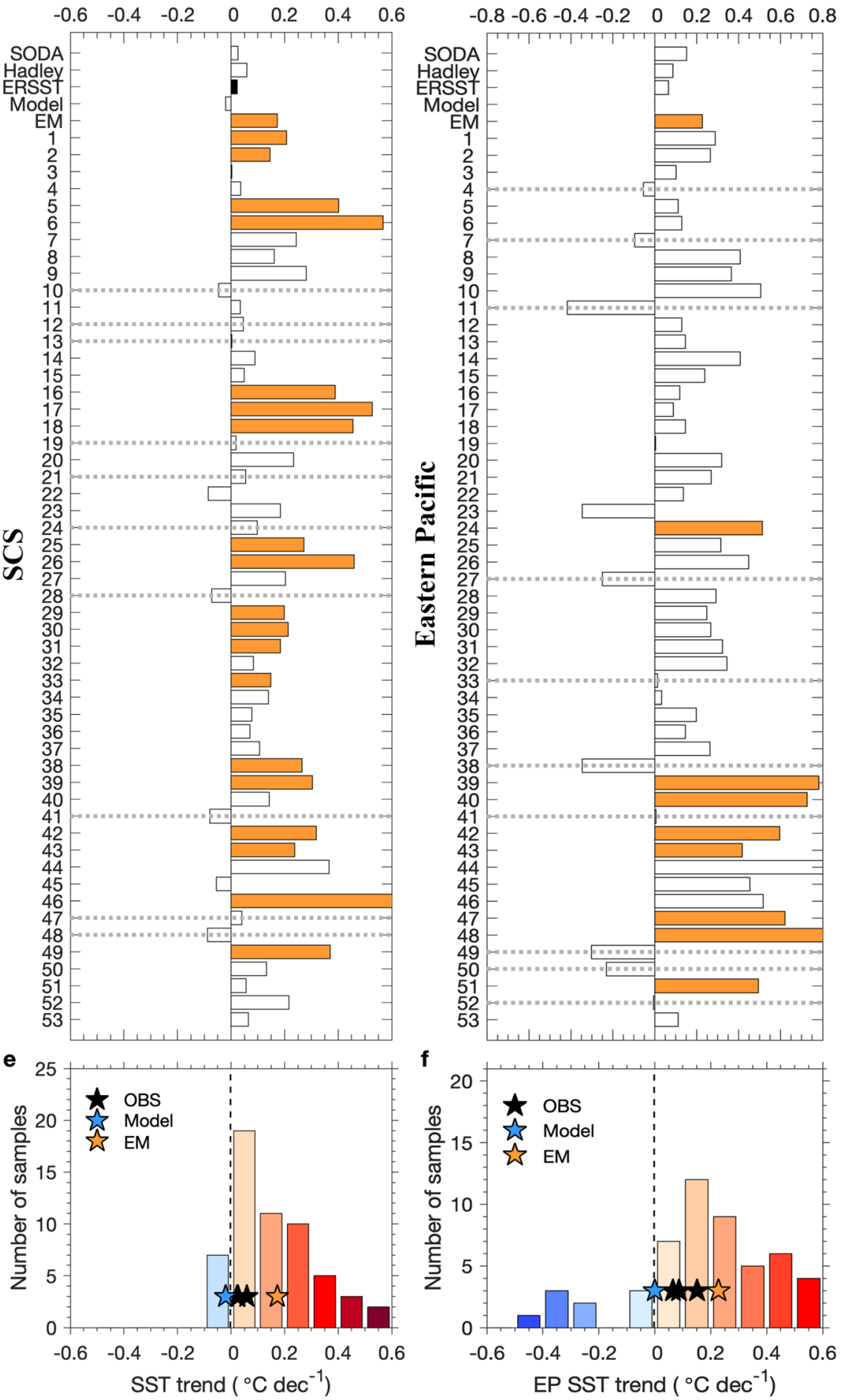

Fig. 11 SCS and eastern Tropical Pacific SST trends. a The SCS SST trends from 3 observations, RegCM-FVCOM model and 53 CMIP5 RCP45 runs during 1970-1997. b Similar with a, but for the trends during 1999-2015. c, similar with b, but for eastern Tropical Pacific. Each number of 1-53 corresponds to one simulation listed in Table 1. The solid filled bars represent the trends reach $90 \%$ significant level, while the white blank bars are not. The grey dashed lines highlight those good CMIP5 members successfully capturing the slowdown of SST warming. d-f Frequency distribution of SST linear trend corresponding to a-c respectively. The stars indicate the trends distribution of observations (black stars), RegCM-FVCOM (blue star) and CMIP5 ensemble mean (orange star) 
Table 1 List of CMIP5 simulations, corresponding to the number indices in Figs. 11, 13 and 14

\begin{tabular}{lll}
\hline 01 ACCESS1-0_r1i1p1 & 19 CSIRO-Mk3-6-0_r3i1p1 & 37 inmcm4_r1i1p1 \\
02 ACCESS1-3_r1i1p1 & 20 CSIRO-Mk3-6-0_r4i1p1 & 38 IPSL-CM5A-LR_r2i1p1 \\
03 CCSM4_r1i1p1 & 21 CSIRO-Mk3-6-0_r5i1p1 & 39 IPSL-CM5A-LR_r3i1p1 \\
04 CCSM4_r2i1p1 & 22 CSIRO-Mk3-6-0_r6i1p1 & 40 IPSL-CM5A-LR_r4i1p1 \\
05 CCSM4_r3i1p1 & 23 CSIRO-Mk3-6-0_r7i1p1 & 41 IPSL-CM5A-MR_r1i1p1 \\
06 CCSM4_r4i1p1 & 24 CSIRO-Mk3-6-0_r8i1p1 & 42 IPSL-CM5B-LR_r1i1p1 \\
07 CCSM4_r5i1p1 & 25 CSIRO-Mk3-6-0_r9i1p1 & 43 MIROC-ESM-CHEM_r1i1p1 \\
08 CCSM4_r6i1p1 & 26 GFDL-CM3_r1i1p1 & 44 MIROC-ESM_r1i1p1 \\
09 CESM1-BGC_r1i1p1 & 27 GFDL-ESM2G_r1i1p1 & 45 MIROC5_r1i1p1 \\
10 CESM1-CAM5_r1i1p1 & 28 GFDL-ESM2M_r1i1p1 & 46 MIROC5_ri1p1 \\
11 CESM1-CAM5_r2i1p1 & 29 GISS-E2-H-CC_r1i1p1 & 47 MIROC5_r3i1p1 \\
12 CESM1-CAM5_r3i1p1 & 30 GISS-E2-H_r1i1p1 & 48 MPI-ESM-LR_r1i1p1 \\
13 CMCC-CM_r1i1p1 & 31 GISS-E2-H_r1i1p2 & 49 MPI-ESM-LR_r2i1p1 \\
14 CMCC-CMS_r1i1p1 & 32 GISS-E2-H_r1i1p3 & 50 MPI-ESM-LR_r3i1p1 \\
15 CNRM-CM5_r1i1p1 & 33 GISS-E2-R-CC_r1i1p1 & 51 MPI-ESM-MR_r1i1p1 \\
16 CSIRO-Mk3-6-0_r10i1p1 & 34 GISS-E2-R_r1i1p1 & 52 MRI-CGCM3_r1i1p1 \\
17 CSIRO-Mk3-6-0_r1i1p1 & 35 GISS-E2-R_r1i1p2 & 53 NorESM1-M_r1i1p1 \\
18 CSIRO-Mk3-6-0_r2i1p1 & 36 GISS-E2-R_r1i1p3 & \\
\hline
\end{tabular}

Acknowledgements This study was supported by the Guangdong Province Key Area Research and Development Program (2020B1111020003), the National Natural Science Foundation of China (41976007 and 91958101), the Special Expert of Guangxi Zhuang Autonomous Region (2018B08) and the China Scholarship Council (CSC). M.L. was supported by Guangdong Basic and Applied Basic Research Foundation (grant 2019A1515011245). We thank Prof. Chien Wang of MIT for providing important comments on this work. We thank the European Centre for Medium-Range Weather Forecasts (ECMWF, http://apps.ecmwf.int/datasets/) for providing the ERA-40 reanalysis for the atmospheric boundary conditions, the Simple Ocean Data Assimilation (SODA) reanalysis (http://www.atmos. umd.edu/ ocean/) for the oceanic boundary conditions, the Hadley Center of the SST observational products (https://www.metoffice.gov. uk/hadobs/hadisst/), the National Oceanic and Atmospheric Administration (NOAA) for the ERSST data (https://www.ncdc.noaa.gov/ data-access/marineocean-data/extended-reconstructed-sea-surfacetemperature-ersst-v5), the NOAA for the Optimum Interpolation Sea Surface Temperature (OISST) data (https://www.ncdc.noaa.gov/oisst), and the NOAA National Center for Environmental Prediction (NCEP) for providing the NCEP/NCAR reanalysis data (https://www.esrl.noaa. gov/psd/data/gridded/data.ncep.reanalysis.html).

Open Access This article is licensed under a Creative Commons Attribution 4.0 International License, which permits use, sharing, adaptation, distribution and reproduction in any medium or format, as long as you give appropriate credit to the original author(s) and the source, provide a link to the Creative Commons licence, and indicate if changes were made. The images or other third party material in this article are included in the article's Creative Commons licence, unless indicated otherwise in a credit line to the material. If material is not included in the article's Creative Commons licence and your intended use is not permitted by statutory regulation or exceeds the permitted use, you will need to obtain permission directly from the copyright holder. To view a copy of this licence, visit http://creativecommons.org/licenses/by/4.0/.

\section{References}

Abraham JP et al (2013) A review of global ocean temperature observations: implications for ocean heat content estimates and climate change. Rev Geophys 51:450-483
Balmaseda MA, Trenberth KE, Källén E (2013) Distinctive climate signals in reanalysis of global ocean heat content. Geophys Res Lett 40:1754-1759

Carton JA, Giese BS (2008) A reanalysis of ocean climate using simple ocean data assimilation (SODA). Mon Weather Rev 136:2999-3017

Carton JA, Chepurin GA, Chen L (2018) SODA3: a new ocean climate reanalysis. J Clim 31:6967-6983

Chen X, Tung KK (2014) Climate. Varying planetary heat sink led to global-warming slowdown and acceleration. Science 345:897-903

Chen CS, Liu HD, Beardsley RC (2003a) An unstructured grid, finite-volume, three-dimensional, primitive equations ocean model: application to coastal ocean and estuaries. J Atmos Ocean Technol 20:159-186

Chen JM, Chang CP, Li T (2003b) Annual cycle of the South China Sea surface temperature using the NCEP/NCAR reanalysis. J Meteorol Soc Jpn 81:879-884

Dai A, Fyfe JC, Xie S-P, Dai X (2015) Decadal modulation of global surface temperature by internal climate variability. Nat Clim Change 5:555-559

Ding H, Greatbatch RJ, Park W, Latif M, Semenov VA, Sun XG (2014a) The variability of the East Asian summer monsoon and its relationship to ENSO in a partially coupled climate model. Clim Dyn 42:367-379

Ding H, Greatbatch RJ, Park W, Latif M, Semenov VA, Sun X (2014b) The variability of the East Asian summer monsoon and its relationship to ENSO in a partially coupled climate model. Clim Dyn 42:367-379

Du Y, Qu T (2010) Three inflow pathways of the Indonesian throughflow as seen from the simple ocean data assimilation. Dyn Atmos Oceans 50:233-256

England MH et al (2014) Recent intensification of wind-driven circulation in the Pacific and the ongoing warming hiatus. Nat Clim Change 4:222-227

Gordon AL (1986) Interocean exchange of thermocline water. J Geophys Res 91:5037-5046

Gordon AL, Huber BA, Metzger EJ, Susanto RD, Hurlburt HE, Adi TR (2012) South China Sea throughflow impact on the Indonesian throughflow. Geophys Res Lett 39:11

Grell GA, Dudhia J, Stauffer DR (1994) A description of the fifthgeneration Penn State/NCAR mesoscale model (MM5). Mesoscale and Microscale Meteorology Division, National Center 
for Atmospheric Research, Tech. Note NCAR/TN-398 + STR, $122 \mathrm{pp}$

Guo YP, Tan ZM (2018) Westward migration of tropical cyclone rapid-intensification over the Northwestern Pacific during short duration El Nino. Nat Commun 9:1507

He Z, Wu R (2013) Coupled seasonal variability in the South China Sea. J Oceanogr 69:57-69

He L, Zhang A, Weese D, Li S, Li J, Zhang J (2014) Demographic response of cutlassfish (Trichiurus japonicus and T. nanhaiensis) to fluctuating palaeo-climate and regional oceanographic conditions in the China seas. Sci Rep 4:6380

Huber M, Knutti R (2014) Natural variability, radiative forcing and climate response in the recent hiatus reconciled. Nat Geosci 7:651-656

Jiang GQ, Xu J, Wei J (2018) A deep learning algorithm of neural network for the parameterization of typhoon-ocean feedback in typhoon forecast models. Geophys Res Lett 45:3706-3716

Jiang GQ, Wei J, Malanotte-Rizzoli P, Li M, Gordon AL (2019) Seasonal and interannual variability of the subsurface velocity profile of the indonesian throughflow at Makassar Strait. J Geophys Res Oceans 124:9644-9657

Jin Q, Wang C (2017) A revival of Indian summer monsoon rainfall since 2002. Nat Clim Change 7:587-594

Kalnay E et al (1996) The NCEP/NCAR 40-year reanalysis project. B Am Meteorol Soc 77:437-471

Kiehl JT, Hack JJ, Bonan GB, Boville BA, Briegleb BP (1996) Description of the NCAR community climate model (CCM3). NCAR Technical Note, 108(2):55-60

Klein SA, Soden BJ, Lau NC (1999) Remote sea surface temperature variations during ENSO: Evidence for a tropical atmospheric bridge. J Clim 12:917-932

Kosaka Y, Xie SP (2013) Recent global-warming hiatus tied to equatorial Pacific surface cooling. Nature 501:403-407

Lee S-K, Park W, Baringer MO, Gordon AL, Huber B, Liu Y (2015) Pacific origin of the abrupt increase in Indian Ocean heat content during the warming hiatus. Nat Geosci 8:445-449

Levitus S, Antonov JI, Boyer TP, Locarnini RA, Garcia HE, Mishonov AV (2009) Global ocean heat content 1955-2008 in light of recently revealed instrumentation problems. Geophys Res Lett 36:L07608

Li M, Gordon AL, Wei J, Gruenburg LK, Jiang G (2018) Multidecadal timeseries of the Indonesian throughflow. Dyn Atmos Oceans 81:84-95

Li M, Wei J, Wang D, Gordon AL, Yang S, Malanotte-Rizzoli P, Jiang G (2019) Exploring the importance of the MindoroSibutu pathway to the upper-layer circulation of the South China Sea and the Indonesian throughflow. J Geophys Res Oceans 124:5054-5066

Li M, Gordon AL, Gruenburg LK, Wei J, Yang S (2020) Interannual to decadal response of the Indonesian throughflow vertical profile to Indo-Pacific forcing. Geophys Res Lett 47:11

Lin CY, Ho CR, Zheng Q, Huang SJ, Kuo NJ (2011a) Variability of sea surface temperature and warm pool area in the South China Sea and its relationship to the western Pacific warm pool. J Oceanogr 67(6):719-724

Lin CY, Ho CR, Zheng Q, Kuo NJ, Chang P (2011b) Warm pool variability and heat flux change in the global oceans. Glob Planet Change 77:26-33

Liu WT, Xie X (1999) Spacebased observations of the seasonal changes of South Asian monsoons and oceanic responses. Geophys Res Lett 26:1473-1476

Liu Q, Yang H, Liu Z (2001) Seasonal features of the Sverdrup circulation in the South China Sea. Prog Nat Sci 11:205-206

Liu Q, Feng M, Wang D (2011) ENSO-induced interannual variability in the southeastern South China Sea. J Oceanogr 67:127-133
McGregor S, Timmermann A, Stuecker MF, England MH, Merrifield M, Jin F-F, Chikamoto Y (2014) Recent Walker circulation strengthening and Pacific cooling amplified by Atlantic warming. Nat Clim Change 4:888-892

Medhaug I, Stolpe MB, Fischer EM, Knutti R (2017) Reconciling controversies about the "global warming hiatus." Nature 545:41-47

Meehl GA, Arblaster JM, Fasullo JT, Hu A, Trenberth KE (2011) Model-based evidence of deep-ocean heat uptake during surface-temperature hiatus periods. Nat Clim Change 1:360-364

Mellor GL, Yamada T (1982) Development of a turbulence closure model for geophysical fluid problems. Rev Geophys 20:851-875

Metzger EJ, Hurlburt HE (1996) Coupled dynamics of the South China Sea, the Sulu Sea, and the Pacific Ocean. J Geophys Res C Oceans 101:12331-12352

Pal JS et al (2007) Regional climate modeling for the developing world - the ICTP RegCM3 and RegCNET. B Am Meteorol Soc 88:1395

Qu T (2000) Upper-layer circulation in the South China Sea. J Phys Oceanogr 30:1450-1460

Qu T (2001) Role of ocean dynamics in determining the mean seasonal cycle of the South China Sea surface temperature. J Geophys Res Oceans 106:6943-6955

Ramanathan V, Collins W (1991) Thermodynamic regulation of Ocean Warming by cirrus clouds deduced from observations of the 1987 El-Nino. Nature 351:27-32

Rayner NAA, Parker DE, Horton EB, Folland CK, Alexander LV, Rowell DP, Kaplan A (2003) Global analyses of sea surface temperature, sea ice, and night marine air temperature since the late nineteenth century. J Geophys Res Atmos 108:D14

Santer BD et al (2014) Volcanic contribution to decadal changes in tropospheric temperature. Nat Geosci 7:185-189

Sillmann J, Donat MG, Fyfe JC, Zwiers FW (2014) Observed and simulated temperature extremes during the recent warming hiatus. Environ Res Lett 9(6):064023

Smagorinsky J (1963) General circulation experiments with the primitive equations: I. The basic experiment. Mon Weather Rev 91:99-164

Smith TM, Reynolds RW, Peterson TC, Lawrimore J (2008) Improvements to NOAA's historical merged land-ocean surface temperature analysis (1880-2006). J Clim 21:2283-2296

Taylor KE, Stouffer RJ, Meehl GA (2012) An overview of Cmip5 and the experiment design. B Am Meteorol Soc 93:485-498

Thompson B, Tkalich P, Malanotte-Rizzoli P (2017) Regime shift of the South China Sea SST in the late 1990s. Clim Dyn 48(5-6):1873-1882

Tong H, Cai L, Zhou G, Yuan T, Zhang W, Tian R, Qian PY (2017) Temperature shapes coral-algal symbiosis in the South China Sea. Sci Rep 7(1):1-12

Tranchant B, Reffray G, Greiner E, Nugroho D, Koch- Larrouy A, Gaspar P (2016) Evaluation of an operational ocean model configuration at 1/128 spatial resolution for the Indonesian seas (NEMO2.3/ INDO12)—part 1: ocean physics. Geosci Model Dev 9:10371064. https://doi.org/10.5194/gmdd-8-6611-2015

Trenberth KE, Fasullo JT (2013) An apparent hiatus in global warming? Earth's Future 1:19-32

Uhlhorn EW, Shay LK (2013) Loop current mixed layer energy response to Hurricane Lili (2002). Part II: idealized numerical simulations. J Phys Oceanogr 43:1173-1192

Uppala SM et al (2005) The ERA-40 re-analysis. Q J R Meteorol Soc 131:2961-3012

Van Sebille E, Sprintall J, Schwarzkopf FU, Sen Gupta A, Santoso A, England MH, Biastoch A, Böning CW (2014) Pacific-to-Indian Ocean connectivity: Tasman leakage, Indonesian throughflow, and the role of ENSO. J Geophys Res Oceans 119:1365-1382. https:// doi.org/10.1002/2013JC009525 
Wang B, Wu RG, Fu XH (2000) Pacific-East Asian teleconnection: how does ENSO affect East Asian climate? J Clim 13:1517-1536

Watanabe M, Shiogama H, Tatebe H, Hayashi M, Ishii M, Kimoto M (2014) Contribution of natural decadal variability to global warming acceleration and hiatus. Nat Clim Change 4:893-897

Wei J, Malanotte-Rizzoli P, Eltahir EAB, Xue P, Xu D (2013) Coupling of a regional atmospheric model (RegCM3) and a regional oceanic model (FVCOM) over the maritime continent. Clim Dyn 43:1575-1594

Wei J, Wang D, Li M, Malanotte-Rizzoli P (2014) Coupled seasonal and intraseasonal variability in the South China Sea. Clim Dyn 44:2463-2477

Wei J, Malanotte-Rizzoli P, Li M-T, Wang H (2016a) Decomposition of thermal and dynamic changes in the South China Sea induced by boundary forcing and surface fluxes during 1970-2000. J Geophys Res Oceans 121:7953-7972

Wei J, Li MT, Malanotte-Rizzoli P, Gordon AL, Wang DX (2016b) Opposite variability of Indonesian throughflow and South China Sea throughflow in the Sulawesi Sea. J Phys Oceanogr 46:3165-3180

Wu R (2010) Subseasonal variability during the South China Sea summer monsoon onset. Clim Dyn 34(5):629-642

Wu L, Liu Z, Gallimore R, Jacob R, Lee D, Zhong Y (2003) Pacific decadal variability: the tropical Pacific mode and the North Pacific mode. J Clim 16:1101-1120
Xiao F, Wang D, Zeng L, Liu QY, Zhou W (2019) Contrasting changes in the sea surface temperature and upper ocean heat content in the South China Sea during recent decades. Clim Dyn 53(3-4):1597-1612

Xu D, Malanotte-Rizzoli P et al (2013) The seasonal variation of the upper layers of the South China Sea (SCS) circulation and the Indonesian through flow (ITF): an ocean model study. Dyn Atmos Oceans 63:103-130

Xue PF, Eltahir EAB, Malanotte-Rizzoli P, Wei J (2014) Local feedback mechanisms of the shallow water region around the maritime continent. J Geophys Res Oceans 119:6933-6951

Yang H, Wu L (2012) Trends of upper-layer circulation in the South China Sea during 1959-2008. J Geophys Res Oceans 117:C08037

Zeng X, Zhao M, Dickinson RE (1998) Intercomparison of bulk aerodynamic algorithms for the computation of sea surface fluxes using TOGA COARE and TAO data. J Clim 11:2628-2644

Zhong Y, Liu Z, Jacob RA (2008) Origin of Pacific multidecadal variability in community climate system model, version 3 (CCSM3): a combined statistical and dynamical assessment. J Clim 21:114-133

Publisher's Note Springer Nature remains neutral with regard to jurisdictional claims in published maps and institutional affiliations. 